\title{
EFFECT OF VASOPRESSIN ON THE UTEROPLACENTAL CIRCULATION: AN ANGIOGRAPHIC STUDY IN THE RABBIT
}

\author{
ANTHONY M. GARTER, JAN GÖTHLIN \\ AND LARS PHILIP BENGTSSON \\ Laboratory of Experimental Roentgenology and \\ Department of Obstetrics and Gynaecology, \\ University Hospital, Lund, Sweden
}

(Received 3rd November 1967)

\begin{abstract}
Summary. The effect of vasopressin on the flow of blood through the uterus and placenta in the rabbit has been investigated by an angiographic technique, with contrast injection through a catheter inserted in the external iliac artery or selectively in the urogenital artery. It was found that the drug markedly reduced contrast filling of the vessels in the placentae and uterine wall including the placental sinuses. It is suggested that this effect was produced by constriction of the venules in the uterine vascular bed. The possible operation of a shunt mechanism in the uterus is discussed.
\end{abstract}

\section{INTRODUGTION}

Experimental angiographic studies of the uterine and placental circulation have been carried out in women (e.g. Borell, Fernström, Ohlson \& Wiqvist, 1964) and the macaque (e.g. Ramsey, Corner \& Donner, 1963) but not in subprimate mammals. It is, however, advantageous to carry out such studies in the rabbit, which is readily available and has a relatively short gestation (31 days). The present communication concerns mainly the effects of vasopressin on the rabbit's uteroplacental circulation and the vessels supplying and draining the uterus.

Vasopressin has been shown to cause a reduction in venous outflow from the rabbit uterus, measured with a drop flowmeter (Carter, Lewis \& Bengtsson, 1966) and in myometrial blood flow, determined by an isotope clearance technique (Garter, Nilsén \& Bengtsson, 1968). Vasopressin's effect on placental circulation in the rabbit has not previously been investigated.

\section{MATERIALS AND METHODS}

Ten white Swedish Land rabbits, between the 12th and 27th days of pregnancy, were used. General anaesthesia was obtained with intravenous pentobarbitone sodium (mebumalnatrium $6 \%, \mathrm{ACO}$, Sweden). The depth of anaesthesia was 
kept as constant as possible throughout each experiment by supplementary doses of pentobarbitone.

Contrast medium was injected through radiopaque, polyethylene catheters inserted through the femoral artery and moved into the desired positions during fluoroscopy. The shapes and positions of the catheter tips were varied as described below. Angiography was performed before, during and after administration of synthetic 8-lysine vasopressin (Postacton ${ }^{\star}$, Ferring, Sweden). Short contrast injections were made either manually with a 2-ml syringe or with the aid of an infusion pump: during the investigation of each animal the rate of

\section{TABLE 1}

SUMMARY OF EXPERIMENTS, SHOWING DRUGS ADMINISTERED AND PROGRAMME FOR ANGIOGRAPHY

\begin{tabular}{|c|c|c|}
\hline \multicolumn{3}{|c|}{ Selective angiography: catheterization of urogenital artery } \\
\hline Expt & Drugs & Angiography \\
\hline 1 & Vasopressin 0.5 i.u. i.a. & $\begin{array}{l}\text { Before and directly after the vasopressin } \\
\text { injection }\end{array}$ \\
\hline 2 & Vasopressin 0.5 i.u. i.a. & $\begin{array}{l}\text { Before vasopressin injection and directly, } \\
5 \mathrm{~min} \text { and } 30 \mathrm{~min} \text { after }\end{array}$ \\
\hline 3 & $\begin{array}{l}\text { (a) Vasopressin } 0.5 \text { i.u. i.a. } \\
\text { (b) Vasopressin } 0.5 \text { i.u. i.a., } 60 \mathrm{~min} \text { after (a) }\end{array}$ & $\begin{array}{l}\text { Before injection and directly and } 30 \mathrm{~min} \\
\text { after } \\
\text { Immediately after the injection }\end{array}$ \\
\hline 4 & $\begin{array}{l}\text { (a) Vasopressin } 0.5 \text { i.u. i.a. } \\
\text { (b) Papaverine } 4 \% 0.2 \mathrm{ml} \text { i.a. }\end{array}$ & $\begin{array}{l}\text { Before injection and directly after } \\
\text { Immediately after the injection }\end{array}$ \\
\hline 5 & $\begin{array}{l}\text { (a) Vasopressin } 0.5 \text { i.u. i.a. } \\
\text { (b) Papaverine } 4 \% 0.4 \mathrm{ml} \text { i.a. }\end{array}$ & $\begin{array}{l}\text { Before injection and directly after } \\
\text { Directly and } 45 \mathrm{~min} \text { after the injection }\end{array}$ \\
\hline
\end{tabular}

Nonselective angiography: catheterization of external iliac artery

\begin{tabular}{|c|c|c|}
\hline Expt & Drugs & Angiography \\
\hline 6 & $\begin{array}{c}\text { Vasopressin at } 2 \mathrm{~m} \text { i.u. } / \mathrm{min} \text { i.v. for } 2 \mathrm{hr} \\
(=0.25 \text { i.u. })\end{array}$ & Before and five times during the infusion \\
\hline 7 & $\begin{array}{l}\text { Vasopressin at } 2 \mathrm{~m} \text { i.u. } / \mathrm{min} \text { i.v. for } 1 \mathrm{hr} \\
(=0.125 \text { i.u. })\end{array}$ & $\begin{array}{l}\text { Before and four times during the infusion } \\
\text { and } 45 \mathrm{~min}, 60 \mathrm{~min} \text { and } 75 \mathrm{~min} \text { after }\end{array}$ \\
\hline 8 & $\begin{array}{l}\text { Vasopressin at } 8 \mathrm{~m} \text { i.u. } / \mathrm{min} \text { i.v. for } 2 \mathrm{hr} \\
(=1.0 \text { i.u. })\end{array}$ & Before and four times during the infusion \\
\hline 9 & $\begin{array}{l}\text { Vasopressin at } 8 \mathrm{~m} \text { i.u. } / \mathrm{min} \text { i.v. for } 1 \mathrm{hr} \\
(=0.5 \text { i.u. })\end{array}$ & $\begin{array}{l}\text { Before and six times during the infusion } \\
\text { and } 30 \mathrm{~min} \text { and } 60 \mathrm{~min} \text { after }\end{array}$ \\
\hline 10 & Vasopressin $10 \cdot 0$ i.u. i.v. & Before and $5 \mathrm{~min}$ after injection \\
\hline
\end{tabular}

contrast injection was kept constant. The contrast medium was Isopaque $60 \%$ (Nyegaard, Norway) or Urografin 76\% (Schering AG, West Germany). Series of envelope-packed films (Crystallex, Kodak, England) were taken by hand changing, the interval between exposures being varied from 2 to $10 \mathrm{sec}$.

In order to obtain as much information as possible, two series of experiments were performed (see Table 1). In five rabbits, catheterization of the urogenital artery was performed, using a catheter with a hooked tip. This technique 
(selective angiography) enabled a high concentration of contrast medium to be obtained in the uterine and placental vessels. Vasopressin was given as a single injection of $0.5 \mathrm{i}$.u. through the catheter, and the effect was studied for up to $30 \mathrm{~min}$. In some cases the results obtained with a second dose of 0.5 i.u. vasopressin, or by giving papaverine $(40 \mathrm{mg} / \mathrm{ml}, \mathrm{ACO}$, Sweden) after vasopressin were studied.

In the remaining five rabbits the tip of a straight catheter was placed in the external iliac artery just below the division of the common iliac artery, and thus near the origin of the urogenital artery (Text-fig. 1). This technique

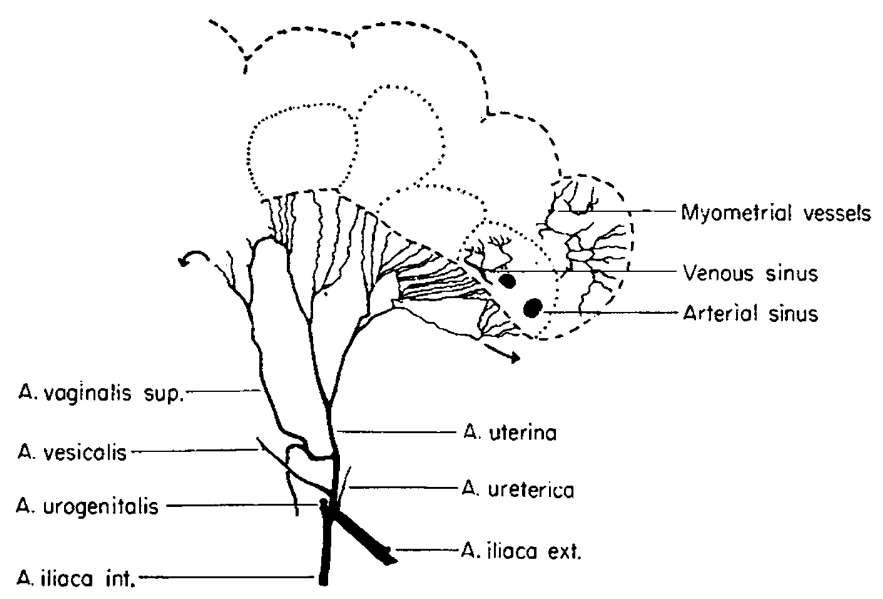

TEXT-FIG. 1. Schematic drawing of the rabbit's urogenital artery in midpregnancy. The arrows indicate anastomoses with the contralateral superior vaginal artery and the ipsilateral ovarian artery.

(non-selective angiography) enabled good contrast filling of both the latter artery and of the major pelvic arteries on that side; giving a more complete picture of vasopressin's effect. The vasopressin was given intravenously. One rabbit received a single injection of $10 \mathrm{i}$.u. and the others were given infusions at rates of 2 or $8 \mathrm{~m}$ i.u. $/ \mathrm{min}$. Angiography was performed periodically throughout infusion and, in two cases, afterwards for 60 and $75 \mathrm{~min}$, respectively.

\section{RESULTS}

The vascular roentgen anatomy of the pelvic region in the female rabbit has been described elsewhere (Göthlin \& Carter, 1968). The main vessels dealt with here are shown in Text-fig. 1. The urogenital artery originates at the division of the common iliac artery into internal and external branches, or a little lower from the internal iliac artery itself. It gives off a small branch to the ureter and a vesical artery to the bladder and thereafter divides to form the superior vaginal and uterine arteries. The branches of the latter two arteries pursue a tortuous course, mainly in the broad ligament, and supply the placentae and a complex of small, anastomosing vessels in the uterine wall. 
The rabbit placenta is haemochorial but, unlike the human placenta, it has a labyrinthine structure: there is nothing which corresponds directly to the so-called intervillous 'space'. The maternal blood runs through a labyrinth of channels in the trophoblast. Beneath this labyrinth is the decidual portion of the placenta, comprising almost exclusively maternal tissues. In this region, the maternal blood from the labyrinth drains into an extensive, irregular sinus system. In addition there are a few large almost spherical sinuses which Mossman (1926) says are arterial. The veins draining the uterus closely follow the arteries, the main vessels draining into the external iliac veins (Barcroft \& Rothschild, 1932).

Since both the distribution of contrast medium and the route of vasopressin administration differed according to the type of catheterization, we shall present the results in two groups.

\section{Selective angiography: catheterization of urogenital artery}

Before vasopressin was given (Pl. 1, Fig. 1; Pl. 2, Figs. 5 and 6), the contrast passed almost exclusively up the urogenital artery, filling the vesical, superior

\section{EXPLANATION OF PLATES 1 TO 3}

\section{PLATE 1}

Rabbit No. 2, 21 days pregnant. Selective catheterization of the right urogenital artery (the right horn has shifted to the left side). Frontal projections taken during four separate contrast injections.

Fig. 1. Before drug administration. There is good filling of myometrial and placental vessels, including sinuses.

FIG. 2. One min after selective injection of 0.5 i.u. vasopressin. Contrast flow to the uterus has ceased.

FIG. 3. Five min after vasopressin. The uterine artery is filled.

FIG. 4. Thirty min after vasopressin. Despite the progressive increase of flow through the uterine artery, there is still no flow through the placentae.

\section{PLATES 2 AND 3}

Rabbit No. 5, 21 days pregnant. Selective catheterization of the left urogenital artery. Frontal projections taken during (arterial phases) and 30 sec after (venous phases) four separate injections of contrast medium.

FIG. 5. Before drug administration. Arterial phase, showing myometrial and placental vessels, including some sinuses.

FIG. 6. Same. Venous phase, showing contrast in the veins and pooling in the spherical placental sinuses.

Fig. 7. Immediately after $0.5 \mathrm{i}$,u. vasopressin. Arterial phase. There is almost no flow through the urogenital artery, but marked contrast spilling to pelvic arteries.

Fig. 8. Same. Venous phase. There is little flow from the uterus and no placental sinuses are visible.

FIG. 9. Immediately after $0.4 \mathrm{ml}$ of $4 \%$ papaverine given 10 min after the vasopressin. Arterial phase. There is dilatation of the urogenital and uterine arteries and some filling of the myometrial and placental vessels but not of the placental sinuses. Note that venous drainage is already apparent (cf. Fig. 5).

FIG. 10. Same. Venous phase, showing high venous contrast density, indicating increased flow.

FIG. 11. Forty-five min after papaverine $(55 \mathrm{~min}$ after vasopressin). Arterial phase. There is again reduced flow through the uterine artery and no myometrial or placental vessels can be seen.

Fig. 12. Same. Venous phase. 
PI.A'TE 1
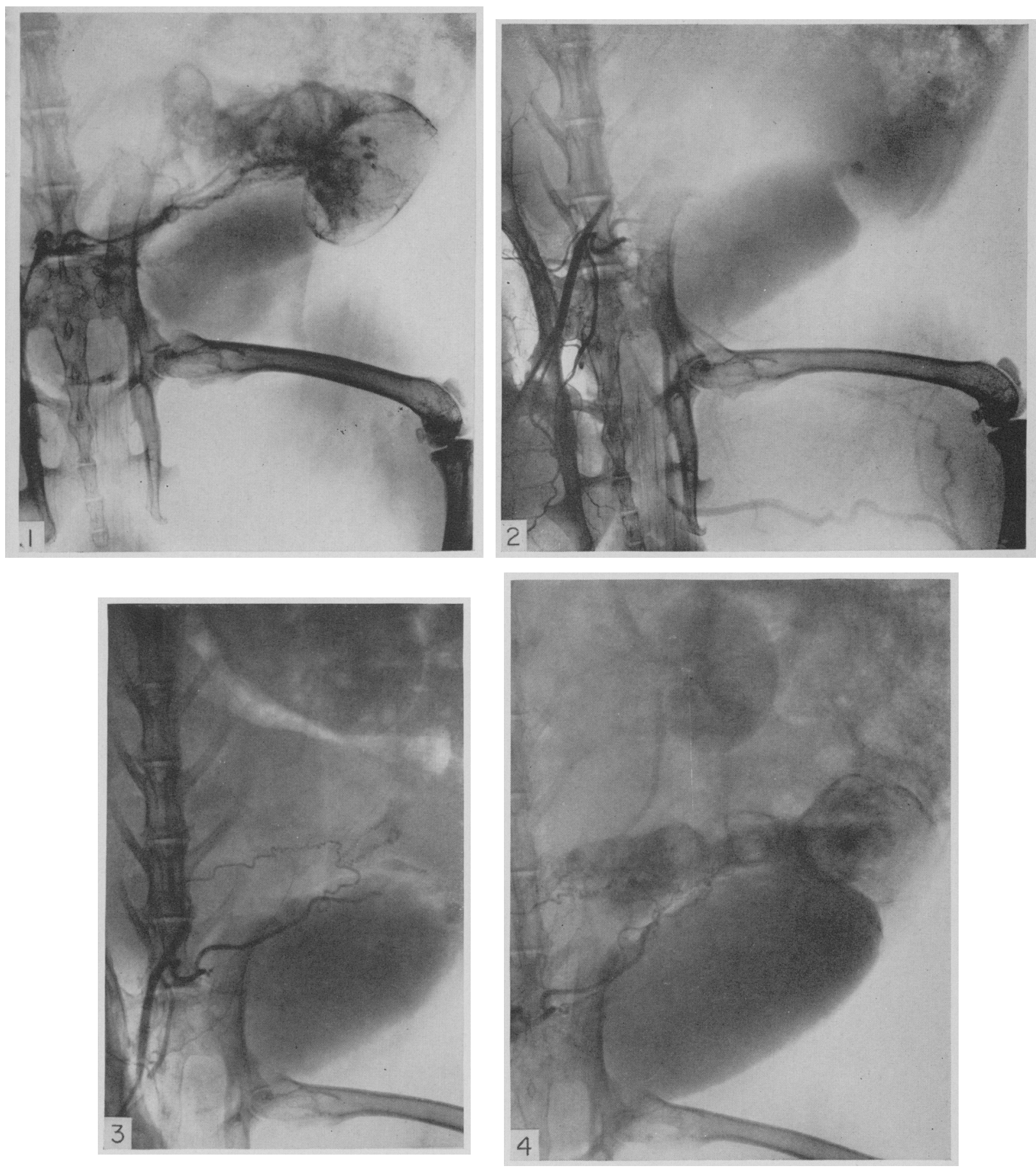

(Facing p. 422) 
PI.ATE 2
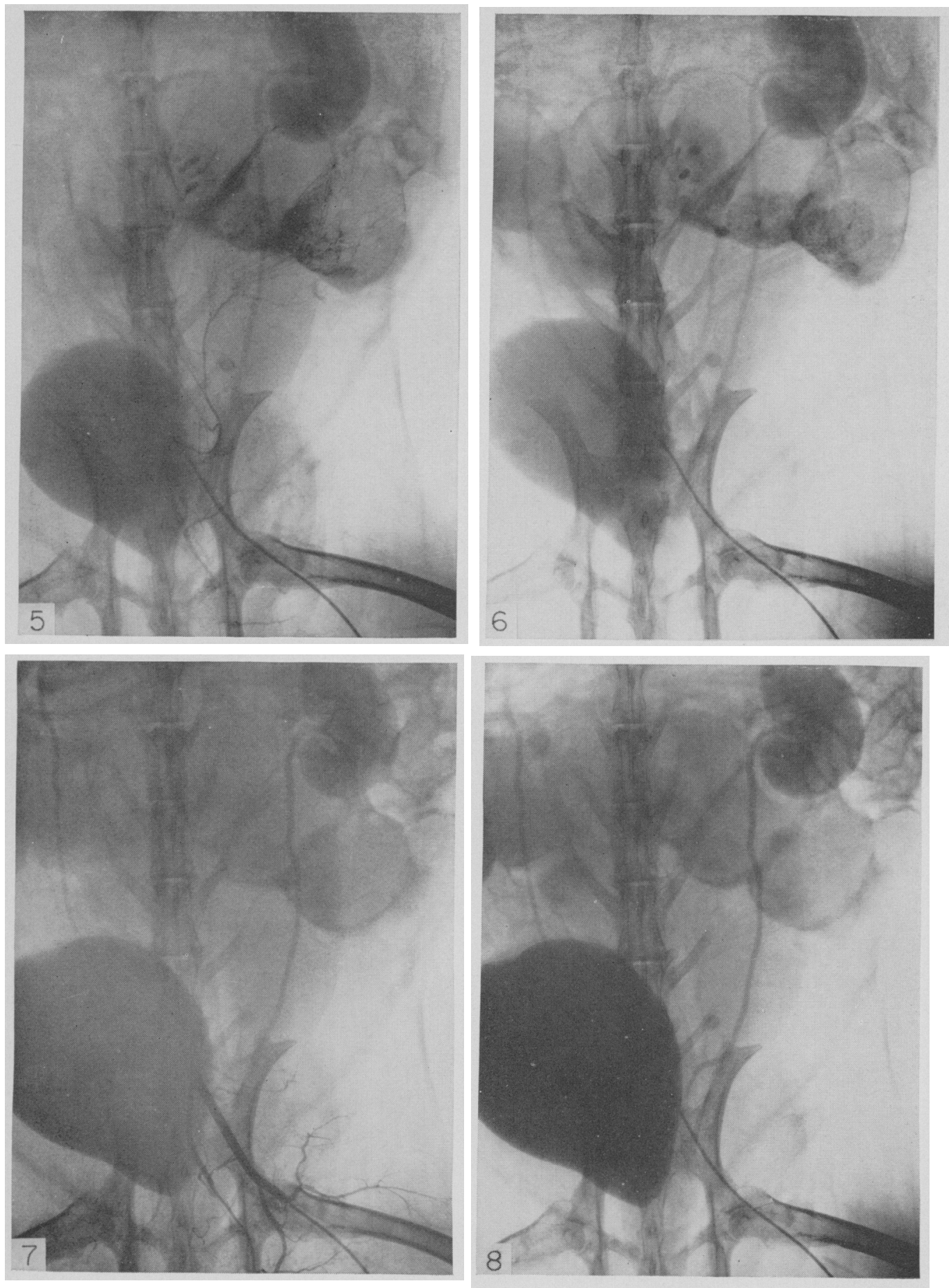
Pl.11F 3
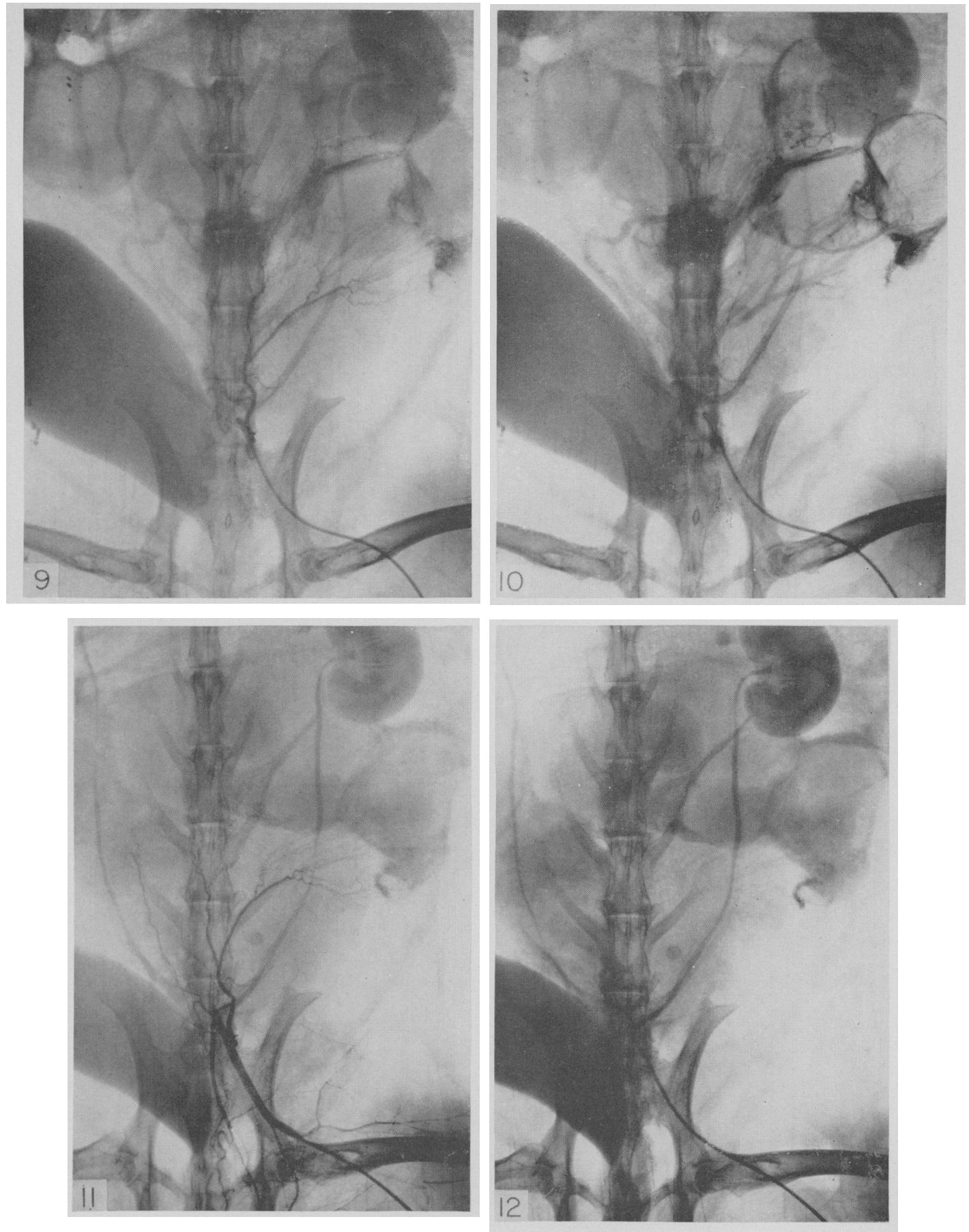
PLATE 4
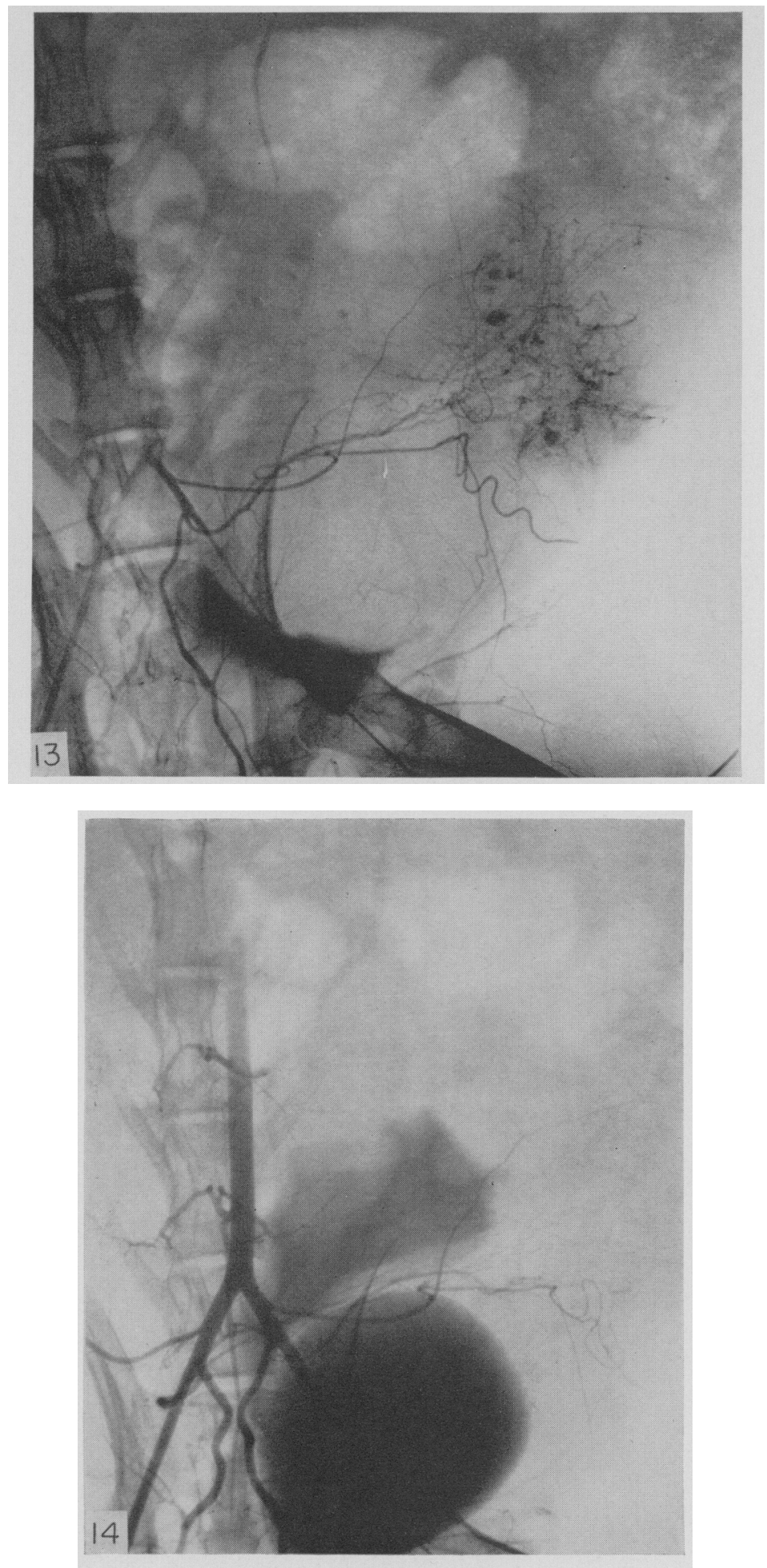
vaginal and uterine arteries. The branches of the latter two arteries were well filled, as was the complex of small, anastomosing vessels in the uterine wall. There was good visualization of the placental vessels, including the irregular venous and spherical arterial sinuses, with considerable pooling of contrast in the latter. The veins draining the uterus were usually seen.

There was an immediate response to 0.5 i.u. vasopressin (Pl. 1, Fig. 2; Pl. 2, Figs. 7 and 8) in all five rabbits, although this varied in degree. The placental vessels and sinuses were not filled except in one case, where they were fewer in number. In no case were the vessels of the uterine wall visualized. The urogenital artery filled normally, but the uterine and vaginal arteries were not filled in three rabbits, although in one of these the vesical artery was traceable. Contrast was always spilled in the main pelvic vessels and aorta. The uterine veins were seen in two rabbits: they showed no change in width, although in one case the contrast density was increased.

In two cases, followed for $30 \mathrm{~min}$ after vasopressin with several angiograms, there was still no filling of the vessels in the placenta (cf. PI. 1, Fig. 4). Filling of the uterine and vaginal arteries improved progressively, however, and spilling decreased markedly. One of these animals was given a second dose of 0.5 i.u. vasopressin $60 \mathrm{~min}$ after the first injection. The response obtained was similar to, but slightly greater than, that obtained with the first dose.

When papaverine was given after vasopressin, the uterine and vaginal arteries and their main branches dilated, so that they were wider than in the control angiograms, and spilling no longer occurred (PI. 3, Fig. 9). The contrast medium filled the veins earlier (Pl. 3, Fig. 9) and the venous contrast density was greater than in control angiograms although there was no change in width (Pl. 3, Fig. 10). Despite this, there was only slight filling of placental vessels, although myometrial filling was improved. In one case angiography was repeated $45 \mathrm{~min}$ after papaverine (Pl. 3, Figs. 11 and 12). There was no longer any filling of placental vessels, spilling had increased and the contrast density in the veins had decreased again.

\section{Non-selective angiography: catheterization of external iliac artery}

Before vasopressin was given (Pl. 4, Fig. 13), contrast filled the urogenital artery and the ipsilateral iliac arteries, with slight or moderate contrast flow to the contralateral side. The uterine and vaginal arteries with branches and the placental vessels were always filled, although not as well as with selective catheterization. The vessels of the uterine wall were rarely distinguishable. The uterine veins could usually be seen.

\section{EXPLANATION OF PLATE 4}

Rabbit No. 8, 21 days pregnant. Catheterization of external iliac artery (non-selective angiography). Frontal projections taken during two separate injections of contrast medium.

Fig. 13. Before drug administration.

FIG. 14. During intravenous infusion of vasopressin at a rate of $8 \mathrm{~m}$ i.u./min: the infusion has been in progress for $30 \mathrm{~min}$. There is a marked reduction in flow to the uterus, and contrast now fills the lower aorta and iliac arteries, with branches, indicating an increase in peripheral resistance. The main arteries of the pelvic region have increased in width. 
Two animals received an i.v. infusion of $2 \mathrm{~m}$ i.u. vasopressin $/ \mathrm{min}$. In one rabbit, filling of the placental sinuses and small branches of the uterine artery was already diminished after $8 \mathrm{~min}$. The vessels decreased progressively in number over the first $30 \mathrm{~min}$ of infusion, with no further change during the remaining $90 \mathrm{~min}$. There were still some small vessels and sinuses filled at the end of the infusion. In the other animal, contrast was injected on the nonpregnant side in a unilateral pregnancy. There was a decrease in the number of visible small arterial branches to the non-pregnant uterine horn after $90 \mathrm{sec}$. No further change was seen during the remainder of the infusion or during 75 min of observation after infusion had been stopped.

In the next two rabbits, i.v. infusion of $8 \mathrm{~m}$ i.u. vasopressin/min gave a more pronounced effect (Pl. 4, Fig. 14). Contrast filling of placental vessels and sinuses decreased rapidly, with no filling at all after 16 and $30 \mathrm{~min}$, respectively. The main arteries of the pelvic region increased in width, and more contrast passed to the contralateral side and aorta. There was a corresponding decrease in filling of the skeletal muscle vessels. In one rabbit, angiography was performed 30 and $60 \mathrm{~min}$ after the end of a $60-\mathrm{min}$ infusion. The placental vessels and sinuses still failed to fill. The main pelvic arteries had decreased somewhat in width, but were still wider than in control angiograms.

Intravenous injection of 10 i.u. vasopressin caused a rapid diminution in the number of uterine and placental vessels seen.

\section{DISGUSSION}

The doses of vasopressin administered caused a reduction in the flow of blood to the uterus and placentae which was usually pronounced and, at least as regards the placentae, long-lasting.

It is well established that vasopressin increases peripheral resistance (McDowall, 1938). This was clearly seen in the non-selective angiograms, where there was decreased filling of skeletal muscle vessels after vasopressin and a correspondingly increased filling of the aorta and major pelvic vessels, including the contralateral common iliac.

We have found no evidence that the urogenital artery or the uterine and vaginal arteries and their branches in the broad ligament constrict after vasopressin. The poorer filling of these vessels after vasopressin therefore seems to depend upon increased resistance beyond them. Such an increase in resistance could be caused by active vasoconstriction or compression of vessels by the contraction of myometrial muscle. It is unlikely that myometrial contraction plays a role since, although vasopressin stimulates myometrial activity in women, it has not been shown to have this effect in rabbits: large doses depress motility and tonus whilst small ones have no effect (Weinstein \& Friedman, 1935; Morgan, 1937; Robson, 1937; Fuchs, 1964).

Constriction of the maternal vessels within the placenta is unlikely to occur since they do not possess a muscular coat, as has been demonstrated histologically (Mossman, 1926). The decreased filling of these placental vessels must, therefore, depend upon constriction of the vessels supplying or draining them. 
Constriction of the large veins draining the uterus can certainly be ruled out, as these were often visible in the angiograms taken after vasopressin and no decrease in their width was seen.

It seems most likely that vasopressin acts on the arterioles or venules of the uteroplacental vascular bed, or both. With the type of experiments performed we cannot, at this time, distinguish between arteriolar and venular constriction. It may, however, be mentioned that 2-phenylalanine-8-lysine vasopressin (Octapressin) acts primarily on venules (Cerletti, Weber \& Weidmann, 1963). In a small number of experiments, Morgan (1937) obtained a decrease in uterine volume after administration of vasopressin (pitressin, 1.0 i.u., i.v.) to non-pregnant rabbits.

When papaverine was given after vasopressin, the uterine artery dilated and the flow through the artery and its branches and the uterine veins increased. These vessels also showed a higher contrast concentration than in control angiograms. Nevertheless, there was still reduced flow through the myometrium and placentae. Forty-five min later, the dilatation of the uterine artery had largely subsided, the flow through the arteries and veins had diminished again, and no contrast at all was seen in the uterine wall or placentae. In other rabbits, which were followed for 30 to $75 \mathrm{~min}$ after vasopressin, we also saw an improvement in flow through the arteries and veins without a corresponding restoration of the flow through the myometrium and placentae. Here, too, the contrast concentration in the veins was equal to, or higher than, that in controls, although the vessels showed no change in width.

These results together imply that vasopressin remains bound to its receptor sites for a long period, maintaining constriction, but that the blood by-passes the placentae through shunts, the opening of which is facilitated by papaverine. Since the appearance of the shunts after vasopressin is generally delayed and their operation diminishes after the papaverine effect wears off, it is probable that even they are constricted by vasopressin. The question of shunting and the effects of drugs upon it deserves thorough investigation.

Morgan (1937) observed that vasopressin (pitressin, 1.0 i.u., i.v.) caused blanching of the rabbit uterus accompanied by a brief contraction, whereafter the uterus relaxed and assumed a cyanotic colour. This did not pass off for at least $30 \mathrm{~min}$, an observation which supports our view that vasopressin has a long-lasting effect on the uterus. We have shown, in particular, that the flow of blood to the placentae is markedly reduced, which must result in foetal anoxia. Large doses of vasopressin are known to cause foetal death in the rat (Byrom, 1937) and mouse (Parkes, 1930) and posterior pituitary extract, containing vasopressin, has the same effect in rabbits (Knaus, 1926).

\section{AGKNOWLEDGMENTS}

This investigation was supported by The Ford Foundation. One of us (A.M.C.) received a personal grant from The Wellcome Trust.

\section{REFERENCES}

BARCroft, J. \& Rothschild, P. (1932) The volume of blood in the uterus during pregnancy. $\mathcal{F}$. Physiol., Lond. 76, 447. 
Borell, U., Fernström, I., Ohlson, L. \& Wigvist, N. (1964) Effect of uterine contractions on the human uteroplacental blood circulation. Am. 7. Obstet. Gynec. 89, 881.

Byrom, F. B. (1937) Morbid effects of vasopressin on the organs and vessels of rats. F. Path. Bact. 45, 1.

Carter, A. M., Lewis, P. J. \& Bengtsson, L. P. (1966) Effects of vasopressin on uterine blood flow in the rabbit. Acta pharmac. tox. 24, 435.

Carter, A. M., Nilsén, R. \& Bengtsson, L. P. (1968) The effect of vasopressin on myometrial blood flow in the pregnant rabbit. Acta pharmac. tox. 26, 29.

Cerletti, A., Weber, H. \& Weidmann, H. (1963) Zur Wirkung von Phenylalanine ${ }^{2}$-Lysin-Vasopressin (Octapressin) auf den arteriellen und venösen Anteil eines peripheren Gefässgebietes. Helv. physiol. pharmac. Acta, 21, 394.

Fuchs, A. R. (1964) Effect of adrenaline and vasopressin on the uterine response to oxytocin in conscious rabbits. Acta endocr., Copenh. 45, 272.

Göthlin, J. \& CarTer, A. M. (1968) Pelvic angiography in the female rabbit. Investve Radiol. (In press).

KNaUs, H. H. (1926) The action of pituitary extract upon the pregnant uterus of the rabbit. F. Physiol., Lond. 61, 383.

McDowall, R. J. S. (1938) The control of the circulation of the blood, chap. 21. Longmans, Green, London.

Morgan, T. N. (1937) An analysis of the action of posterior pituitary extracts on the uterus. F. Pharmac. exp. Ther. 59, 211.

Mossman, H. W. (1926) The rabbit placenta and the problem of placental transmission. Am. F. Anat. $37,433$.

Parkes, A. S. (1930) On the synergism between oestrin and oxytocin. F. Physiol., Lond. 69, 463.

RAMSEy, E. M., Corner, G. W. \& DonNer, M. W. (1963) Serial and cineradioangiographic visualization of maternal circulation in the primate (hemochorial) placenta. Am. F. Obstet. Gynec. 86, 213.

Robson, J. M. (1937) The action of progesterone on the uterus of the rabbit and its antagonism by oestrone. 7. Physiol., Lond. 88, 100.

Weinstein, G. L. \& Friedman, M. H. (1935) A pharmacologic study of the uterine fistula of the unanaesthetized rabbit. I. Pituitrin. Am. F. Obstet. Gynec. 29, 93. 